\title{
Developing Effective Health Communication Campaigns
}

https://doi.org/10.21814/uminho.ed.46.4

\section{Ralph Tench ${ }^{1}$ \& Gemma Bridge ${ }^{2}$}

1,2 Leeds Business School, Leeds Beckett University, Leeds, United Kingdom

${ }^{1}$ https://orcid.org/0000-0001-7760-2606; ${ }^{2}$ https://orcid.org/0000-0003-3888-0202 



\begin{abstract}
Health communication campaigns have been used to address many of the most prevalent non-communicable disease risk factors, such as physical inactivity. Typically, campaigns are shared via mass media to reach a high proportion of the population and at a low cost per head. However, the messages shared are in direct competition with other campaigns, such as product marketing, which can result in the campaign not being seen adequately to lead to behaviour change. Moreover, as health campaigns are shared widely, the messages may not be understood or considered appropriate by certain audiences due to their broad nature. This can lead to unintended consequences, such as inadvertent social norming of the risk behaviour. To improve the success of health communication campaigns, they should be based on theory, with the theory of planned behaviour, the elaboration likelihood model, and the extended parallel process model, three of the most widely used. Such theories highlight the importance of targetting a campaign to the audience. Targetting a health communication campaign involves considering the audience in the development and dissemination of the message. Campaigns could also be co-developed with the audience in question to ensure relevance. Digital technologies such as machine learning and artificial intelligence can be used to tailor messages to the target audience effectively. Examples of targetted and broad health communication campaigns are presented.
\end{abstract}

\title{
Keywords
}

health communication, strategic communication, behaviour change, non-communicable diseases, social media

\section{Introduction}

The aim of this chapter is to provide an overview of what health communication is, with a focus on targeted campaigns. Examples of public health communication campaigns are provided, not as a guide for best practice, but as opportunities to develop insights that could inform future strategic communication efforts. The topics covered in the chapter include:

- definition of health communication;

- health communication campaigns and behaviour change; 
- limitations and unintended consequences of communication campaigns;

- theory of successful health communication campaigns;

- targeted health communication campaigns;

- case studies of health communication campaigns;

- conclusion and key takeaways for developers of health communication campaigns.

\section{What is Health Communication?}

Communication involves the exchange of information via multifarious on and offline channels to reach intended audiences. Health communication is fundamental to promoting public health, with the aim of "influencing and supporting individuals, communities, health care professionals, policy makers or special groups to adopt and sustain a behavioural practice or a social or policy change that will ultimately improve health outcomes" (Schiavo, 2007, p. 7). Health communication is multifaceted, drawing on numerous disciplines including strategic communication, marketing, psychology, and health education, and it is relevant across all aspects of health and wellbeing, including quality of life and disease prevention (Rimal \& Lapinski, 2009). Although most often associated with public health, it is also an increasingly important field in the non-profit and commercial sectors (Schiavo, 2007). Communication campaigns in health have been defined as:

purposive attempts to inform or influence behaviours in large audiences within a specified time period using an organized set of communication activities and featuring an array of mediated messages in multiple channels generally to produce non-commercial benefits to individuals and society. (Aitkin \& Rice, 2012, p. 3)

Such campaigns are often shared using mass media, including television, radio or print media, to expose a large proportion of the population to certain messages. Messages can also be shared via digital platforms, such as social media and via blogs.

Health communication campaigns have been used to address many of the most prevalent non-communicable disease risk factors including poor diet, physical inactivity, tobacco use, and alcohol consumption (Peters et 
al., 2019). Such campaigns are considered critical to intervention efforts to improve population health, with greater investment in campaigns linked to greater public health success. For instance, in terms of tobacco control, research indicates that the more that is invested in communication campaigns, the greater the success rate of quit attempts (Kuipers et al., 2018). However, the success of health campaigns is hampered by competition with pre-existing social norms, strong marketing, and pervasive behaviours are driven by habit or addiction (Wakefield et al., 2010). Furthermore, messages can fall short due to factors such as the increasingly fractured and cluttered media environment, the heterogeneous audience which does not respond equally to homogeneous messages, and campaigns that target behaviours that the audience lacks the resources to change (Wakefield et al., 2010).

\section{Public Health Communication Campaigns and Behaviour Change}

Public health communication campaigns can be considered in the context of health education, social marketing or as a combination of both (Zhao, 2020). Educational campaigns are typically clinically or institutionally focussed, whilst social marketing campaigns often have a broader audience and utilise marketing tactics to incentivise behaviour change (Zhao, 2020). Despite their differing contexts and research traditions, health communication campaigns have a similar development process, involving the creation of campaign objectives and message strategies, dissemination of the message via appropriate channels, and the evaluation of the campaign to assess its impact (Rice \& Atkin, 2012). Moreover, irrespective of the context, the aim of health communication campaigns is typically to change behaviour, doing so directly or indirectly (Hornik \& Yanovitzky, 2003). Direct campaigns aim to invoke an emotional response about a certain behaviour or seek to affect decision making before engaging in certain behaviour. In contrast, campaigns that aim to achieve behaviour change indirectly, seek to do so by setting an agenda and increasing discussion about a health issue in a network. Doing so increases the perceived social norm of behaviour and therefore alters an individual's intention of engaging in that behaviour (Wakefield et al., 2010). As communication involves understanding and sharing meanings (Pearson \& Nelson, 1999), whether seeking direct or indirect influence, health communication campaigns need to be based on messages that are easily understood by the intended audience. 


\section{Barriers to the Success of Health Communication Campaigns}

Health communication campaigns are often shared widely via mass media, such as television, radio, and newspapers, to expose large populations to messages (Wakefield et al., 2010). Whilst this approach can ensure a behaviourally focused message reaches a high proportion of the population and at a low cost per head, the messages shared are in direct competition with other factors, such as product marketing. This can reduce the visibility of the campaign message and as behaviour change, requires frequent exposure to the campaign for an adequate period of time (Friedman et al., 2016), such competition can limit the effectiveness of the campaign on long term behaviour change. This has been supported in relation to tobacco control campaigns whereby withdrawal of the campaign reduced the beneficial effects of the messages being shared (Wakefield et al., 2008). Similar results have been indicated in relation to physical activity and nutrition, with behavioural changes not maintained after campaigns end (Cavill \& Bauman, 2004). However, there is a balance to be achieved in terms of adequately sharing health messages, since inertia or lethargy to the message can occur if the audience is exposed too frequently (Illeditsch et al., 2012; Webb \& Byrd-Bredbenner, 2015), or if the individual is exposed to too much information, as has been noted during the COVID-19 "infodemic" (Nielsen et al., 2020; World Health Organization, n.d.).

Other barriers to the success of health communication campaigns include:

- A lack of perceived message applicability (Cho \& Salmon, 2007), which could occur if the message was not pre-tested with the target audience prior to being shared, if the message was not tailored to the appropriate stage of the behaviour change process (Prochaska \& DiClemente, 1983), or if the meaning of the message has been changed, for instance through the addition of comments or images by audience members on social media.

- Inadvertent social norming of the risk behaviour (Cialdini, 2003). This could occur as a result of a campaign aiming to reduce a behaviour by highlighting its prevalence, but instead of reducing the behaviour, the campaign results in that behaviour being perceived as normal, and thus acceptable, by the target audience (Dempsey et al., 2018).

- Pushing the behaviour of the audience in a direction opposite to that which the campaign aimed to achieve (i.e., the boomerang effect; Hart, 2013). This can occur in adolescents due to psychological reactance to 
the "forbidden" behaviours (i.e., the forbidden fruit appeal; Henriksen et al., 2006; Steindl et al., 2015).

- A lack of familiarity with technology and/or the dissemination platform can reduce the frequency with which a target population is exposed to the message, making it important to consider the level of technology use in the target audience (Rimal \& Lapinski, 2009).

\section{What Theoretical Factors Are Associated With a Successful Health Campaign?}

For health communication campaigns to be effective, they need to be based on research evidence and theory. If theories are not considered, health communication campaigns are developed based on trial and error, which will result in inefficient and ineffective results (Zhao, 2020). Numerous theories have been applied to health communication. The most visible of these being behavioural theories which help to explain what drives individual behaviour and how behaviours can change. Communication theories are also used in the development of health campaigns. Such theories highlight that the channel source, the receiver, and the message itself are all essential components of the communication process, and need to be considered when developing a health campaign. Both behavioural and communication theories indicate that information does not fall into a social vacuum, instead, information is received through processes of selective exposure, selective perception, prior knowledge, and macro-social levels, and these can all impact how health campaigns are received and acted upon (Rimal \& Lapinski, 2009). Three of the most widely applied theories to health communication are the theory of planned behaviour, the elaboration likelihood model, and the extended parallel process model.

\section{The Theory of Planned Behaviour}

The theory of planned behaviour (TPB; Ajzen, 1985) proposes that volitional human behaviour is a function of the intention to perform the behaviour and perceived behavioural control. Thus, for health communication campaigns, the TPB suggests that to understand why people behave the way they do, and to, therefore, change that behaviour, we must first understand their intentions. And, those intentions are themselves influenced by attitudes, which represent the judgements people make about a behaviour; subjective norms, which relate to an individual's concern about how a 
group would perceive a certain behaviour and motivations to comply with a group's ideals; and perceived behavioural control, which relates to an individual's belief that they can perform a behaviour and what results that behaviour will lead to (Ajzen, 1991). Thus to achieve a successful health communication campaign, it would be expected that the message must consider the intended audience's attitudes about the behaviour, their subjective norms, and their levels of perceived behavioural control.

Although the TPB is not without criticism, for instance Sheeran et al. (2013) argued that the TPB is overly simplistic as it exclusively focuses on rational reasoning, without consideration of unconscious influences on behaviour, whilst others argue that the TPB has limited predictive validity since it does not explain "inclined abstainers", that is, people who form an intention but fail to act (Orbell \& Sheeran, 1998), the TPB has been extensively applied in the context of health. For instance, it has been explored with smoking (Alanazi et al., 2017; Godin et al., 1992), exercise (Bozionelos \& Bennett, 1999) and food choice (McDermott et al., 2015). Although it has been suggested that the TPB has the potential to inform behaviour change interventions (Rutter, 2010), including health communication campaigns, its use as a basis for campaigns is limited. However, research that has the TPB to both design and evaluate a communication campaign for reducing negative health behaviours found that the TPB informed campaign was able to change behaviour, encouraging drivers to slow down, highlighting the theory's potential to change attitudes (Stead et al., 2005).

\section{Elaboration Liklihood Model}

An alternative theory that has been used in the context of health communication is the elaboration likelihood model (ELM; Petty \& Cacioppo, 1986). The ELM has been applied to improve health outcomes across numerous health issues including smoking (Flynn et al., 2011), nutrition (Wilson, 2007) and reducing risky behaviour in relation to acquired immunodeficiency syndrome (AIDS; Dinoff \& Kowalski, 1999). The ELM has also been used as a framework for exploring the impact of health communication campaigns on attitudes and behaviour (Petty \& Cacioppo, 1986). The key question that the ELM asks is "how do people react to the messages that they are exposed to?". The ELM suggests that some people are engaged by a message and others are not. Those that are involved with the message and understand its content are more likely to be influenced to act and change their behaviour. Those that are not involved with the message can still be 
influenced, but the message must be tailored in a way to catch their attention. By considering how people react, messages in health campaigns can be designed to target the intended audience. The ELM has been used in advertising because it can help messages to be seen and heard in the crowded message space (Cho, 1999). The ELM also highlights that the intended audience needs to understand the information being shared in order to change their behaviour. Although the ELM is an influential and popular framework for exploring attitudinal and behavioural change (Morris et al., 2005), doubts about its predictive abilities have been raised (Szczepanski, 2006). Moreover, the ELM was developed prior to the advent of digital communication technologies such as social media, and therefore it may not be reactive to the current, congested digital landscape (Kitchen, 2013).

\section{Extended Parallel Process Model}

A third theory that has been used to inform health communication campaigns is the extended parallel process model (EPPM; Witte, 1992). The EPPM was based on the health belief model (Rosenstock et al., 1988), which was initially built to improve healthy behaviours by influencing behavioural intention. Although the EPPM considers many of the factors discussed in the TPB and the ELM, it also considers the role of emotion, in particular fear, in understanding and acting upon a health message. The EPPM highlights that because many health behaviours are habitual, a trigger is needed, and that is often tied to fear-based emotions. The EPPM has been applied to understand and explore behavioural changes in several health contexts including breast cancer prevention campaigns (Chen et al., 2019) and reducing risk behaviours in HIV/AIDS (Witte, 1994). These studies have reveleaved that fear is related to an individual's motivation to act, but that the relationship is curvilinear, whereby fear motivates change, but only to a certain point. If individuals become too afraid, they will be crippled and unable to take steps to change. The EPPM thus suggests that whilst fear can be used to motivate behaviour change in health communication campaigns, it must be used with caution, and with consideration of the intended audiences efficacy or belief in their ability to make changes.

Taken together, the TPB, the ELM and the EPPM highlight that for health communication campaigns to be successful, they need to do the following:

- Consider the intended audience's attitudes about the behaviour, their subjective norms and their levels of perceived behavioural control (TPB). 
- Be clear and understandable since those that understand the message content are more likely to be influenced to act and change their behaviour (ELM);

- if the audience is not involved with the message, the message must be tailored in a way to catch their attention (ELM).

- Emotional messages, for instance those using fear, can be effective in motivating change. However, the relationship between fear and motivation is curvilinear (EEPM).

- Fear, if used, needs to be done so with consideration of the intended audience's fear threshold and their perceived levels of self-efficacy (EEPM).

\section{What Is a Targeted Campaign?}

The TPB, ELM, and the EEPM highlight that intentions to act are related to attitudes, social norms, and perceived situational control (Ajzen, 2005), and emphasise the importance of understanding constructs like issue beliefs and personal efficacy as key predictors of campaign resonance. Such factors support the need to consider the audience when delivering a health campaign. In practice, messages tailored to a specific population are more likely to resonate and have an impact as the group is likely to share similar pre-existing behaviours (Snyder, 2007), understandings of the health consequences of the target behaviour (Zhao, 2020), and emotional responses to the messaging (Borawska et al., 2020). As a result, focusing attention on specific subgroups will help to ensure the best return for efforts by boosting chances of campaign effectiveness. In support, Compton and Pfau (2009) found that using inoculation theory, which aims to confer resistance to persuasive influence, as a messaging strategy, could be used effectively to prevent pre-teens from starting smoking but was not successful at altering smoking behaviour in other (Compton \& Pfau, 2009).

\section{Identification of the Target Audience}

To identify the target audience, campaign designers often base their decision on demographic factors such as age, sex, and location (Slater, 1995). However, it can be more helpful to consider theoretically meaningful factors such as determinants of behaviour. By doing so, campaign designers will be better able to assess who is likely to respond to the campaign 
activities, and how likely the audience is to change their behaviour (i.e., are they unaware of the harmful behaviour, are they contemplating changing it, or have they already made a decision to change it; Slater, 1995). By identifying the target audience based on determinants of behaviour, campaign messages are more likely to support the group to move to the next stage of their behaviour change process (Slater, 1999). Previous research indicates that models such as the extended parallel process model (EPPM; Witte, 1994) a model which suggests that behaviour is influenced by an individual's evaluation of perceived and actual efficacy and threat, could be used to aid the process of audience segmentation when determinants of behaviour are the focus (Campo et al., 2012). To understand how responses may vary, representatives from the population of interest could be included in the design of the campaign (Schiavo, 2007).

\section{Dissemination of the Campaign}

Whilst unique campaign approaches are theoretically optimal, in practice, developing a campaign for each target group could be prohibited by time and cost. As an alternative, campaign designers can acknowledge the diversity of their target groups in their campaign but continue to use a standardized message. For instance, the campaign could be adapted based on when and where the messages are shared (Snyder, 2007). Such tailored dissemination approaches vary from traditional large scale health communication campaigns, which have relied on the mass media as the primary vehicle of delivery (Zhao, 2020). Messages could be shared via text message or email, with such digital triggers focusing an individual on a desired goal at a certain time (Muench \& Baumel, 2017). Targetted dissemination could also utilise social media, which in the increasingly mediated world, is growing in importance as a platform for the dissemination of health communication campaigns. However, due to the quantity of information that is presented to audiences via social media, it is important to ensure that the message is given sufficient exposure to ensure that the campaign reaches the target audience with adequate frequency (Zhao, 2020). What is more, if social media is used for dissemination, message fidelity needs to be considered. Although engagement with the post is important, and can increase the reach of the campaign, it can act negatively as the audience could alter the meaning of the campaign message through commenting, reposting, and adding memes or images. Therefore, campaigns on social media will need to be monitored and adjusted to ensure the message retains its original meaning and reaches the targetted audience effectively. 


\section{The Use of Digital Technology to Tailor Messages}

Thanks to developments in digital technology, automated methods for tailoring campaigns and enhancing information relevance for specific audiences are being explored. Such methods are helping to make campaigns tailored for each target group more time and cost efficient. The application of artificial intelligence, through machine learning using both supervised and unsupervised learning algorithms, is of particular interest since it provides a mean to interpret external data correctly, learn from such data, and exhibit flexible adaptation, which could enable campaigns to adapt and meet the needs of the target audience (Kaplan \& Haenlein, 2019), which is important in terms of reducing the "noise" that individuals receive when navigating the mediated world in which we live, where there is a huge amount of information available $24 / 7$ (Tench et al., 2017). Digital technologies such as machine learning could also be used in the monitoring and evaluation stages of health communication campaigns, for instance, helping communicators to analyse communication (e.g., social media posts) to devise future campaigns that are more persuasive for the population of interest (Davenport et al., 2020). Alternative uses of digital technologies in health communication campaigns include monitoring and analysing content on social media to understand population sentiment and/or awareness of a certain topic (Loukis et al., 2017). Such insights would provide valuable data that could be used to further tailor campaigns to the needs of different populations. The use of applications (chatbots) that can interact with users, mimicking human conversations is another potential direction for artificial intelligence in health communication campaigns. Chatbots can understand a spoken language and use speech communication as a user interface (Androutsopoulou et al., 2019; Poola, 2017), and such capabilities could be applied to the context of health communication campaigns to answer questions or share specific information based on the needs of the individual.

\section{Case Studies of Health Communication Campaigns}

\section{Man Therapy, Substance Abuse and Suicide Among Men: Targeted Health Communication Campaign}

"Man therapy" is a targeted health communication campaign that was developed to address high numbers of suicides by men in America. "Man therapy", which was created by the Colorado Office of Suicide Prevention 
in collaboration with the Carson J Spencer Foundation, used humour in its messaging to reach its target audience of working-age men and to reduce the stigma of mental health in the population. The campaign included videos, an online support group and a website (https://www.mantherapy. org/). The resources and the campaign itself were developed following multiple focus groups and in-depth interviews with the target audience (Spencer-Thomas et al., 2012). Although no peer-reviewed evaluations have been conducted (Gretz \& Rings, 2020), internal reports suggest that the campaign reached thousands of men in the target audience, with over 350,000 website visits within 18 months of launch, and encouraged over $50 \%$ of men surveyed to consider seeking mental health support who would not have otherwise done so (Spencer-Thomas et al., 2014). However, even targeted campaigns such as this are not without limitations. As suggested by Mocarski and Butler (2016) in their evaluation of the campaign, using humour as a strategy to reach a target audience can be risky, because the audience must be on the same page as the person leading the campaign for it to be successful (Martin, 2004).

\section{"Stay Alert, Control the Virus, Save Lives": Non-Targeted Communication Campaign}

Following the lifting of the strict lockdown for COVID-19 control in the UK, the UK government released a new campaign with an associated slogan to encourage the population to "stay alert, control the virus, save lives" (Figure 1). The campaign was not targeted and was criticised for being vague, open to interpretation and released out of context, making behavioural responses difficult, if not impossible (Hickman, 2020). Criticism was apparent across social media. For example, world renowned author J. K. Rowling (2020) responded immediately on Twitter stating: "is Coronavirus sneaking around in a fake moustache and glasses? If we drop our guard, will it slip us a Micky Finn? What the hell is 'stay alert' supposed to mean?". Such criticism resulted in the government releasing a follow-up announcement on social media to clarify their message, but even that was not received well. Many again criticised the campaign stating that the second message highlighted the ambiguity of the slogan and complicated the messaging. 


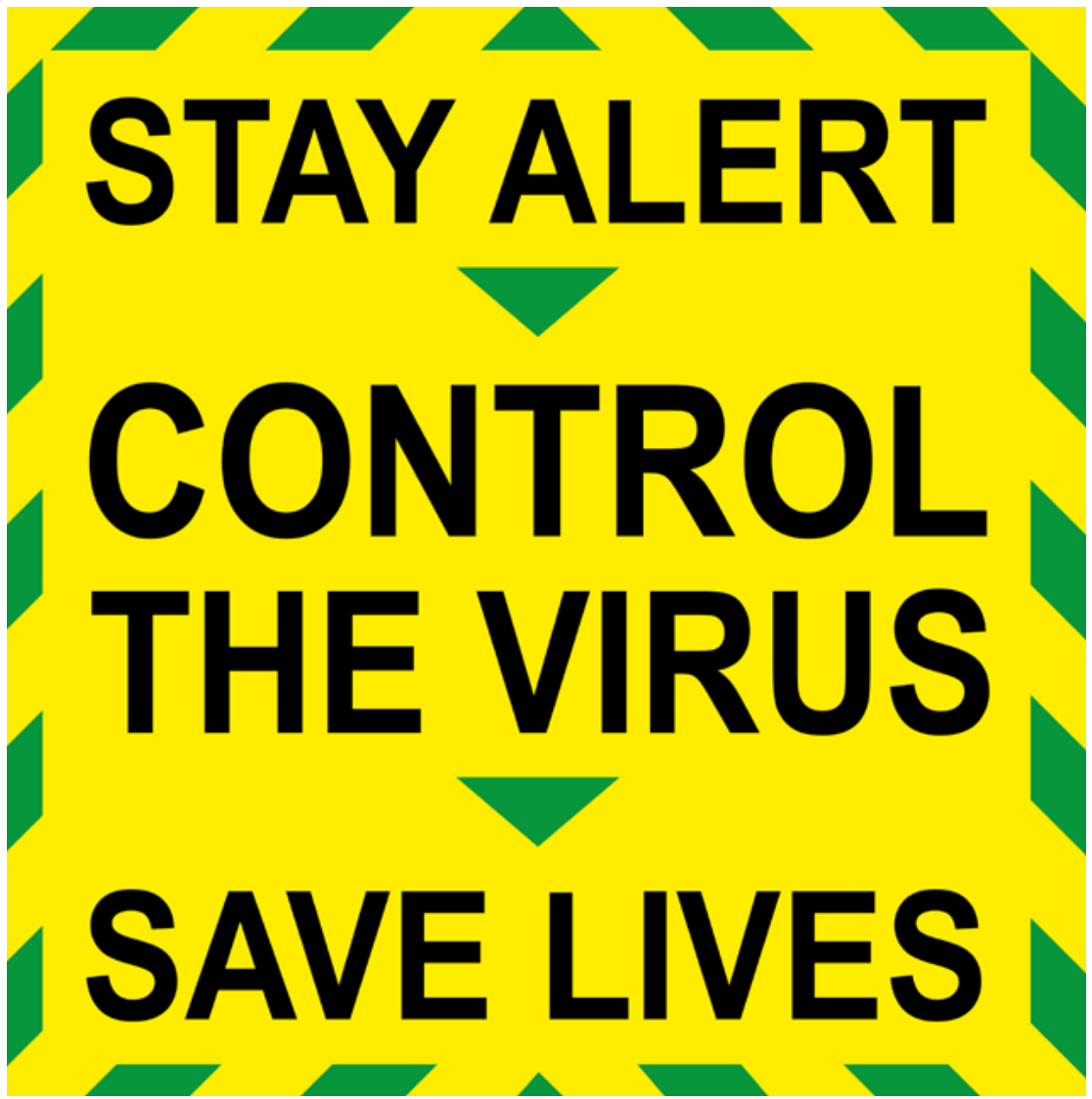

Figure 1 UK government slogan, release as the initial lockdown was eased. Credits. Jon Le-Bon - stock.adobe.com

\section{Conclusion}

Public health communication campaigns can positively alter health-related behaviours such as smoking, tobacco use, and inadequate physical activity. However, due to the mediated world in which we live, where information is available 24/7, and the pervasive marketing efforts of multi-national corporations, health campaigns must be carefully planned to ensure the target audience is exposed to planned messages frequently enough to enable them to take in the messages and respond. For optimal return on campaign investment, health communication campaigns must be tailored to the audience. All public health communication campaigns 
should be monitored to ensure messages are not altered, and finally, campaigns should undergo rigorous independent assessment upon completion to ensure learnings are captured and future campaigns can be improved.

\section{Key Takeaways for Health Communicators}

- Tailor messages to the target audience to ensure the messages are understood and can achieve the greatest impact.

- Use a multidisciplinary approach to the development of health communication campaigns, incorporating expertise from a variety of professional backgrounds and insights from the target audience.

- Pre-test messages to guard against unintended consequences and to ensure that the messages resonate with the intended audience.

- Sufficient funding should be reserved for health communication campaigns to ensure the audience are exposed to messages continuously over time.

- Monitor campaigns shared via social media and be prepared to adjust messages if altered by the audience.

\section{References}

Aitkin, C., \& Rice, R. (2012). Theory and principles of public communication campaign. In C. Aitkin \& R. Rice (Eds.), Public communication campaigns (pp. 2-20). Sage Publications.

Ajzen, I. (1985). From intentions to actions: A theory of planned behavior. In J. Kuhl \& J. Beckmann (Eds.), Action control (pp. 11-39). Springer Berlin Heidelberg.

Ajzen, I. (1991). The theory of planned behavior. Organizational behavior and human decision processes, 50(2), 179-211. https://doi.org/10.1016/0749-5978(91)90020-T

Ajzen, I. (2005). Attitudes, personality, and behavior. McGraw-Hill Education.

Alanazi, N. H., Lee, J. W., Dos Santos, H., Job, J. S., \& Bahjri, K. (2017). The use of planned behavior theory in predicting cigarette smoking among waterpipe smokers. Tobacco Induced Diseases, 15(29), 1-8. https://doi.org/10.1186/s12971-017-0133-z

Androutsopoulou, A., Karacapilidis, N., Loukis, E., \& Charalabidis, Y. (2019). Transforming the communication between citizens and government through Al-guided chatbots. Government Information Quarterly, 36(2), 358-367. https://doi.org/10.1016/j.giq.2018.10.001 
Borawska, A., Oleksy, T., \& Maison, D. (2020). Do negative emotions in social advertising really work? Confrontation of classic vs. EEG reaction toward advertising that promotes safe driving. PLOS ONE, 15(5), 1-20. https://doi.org/10.1371/journal.pone.0233036

Bozionelos, G., \& Bennett, P. (1999). The theory of planned behaviour as predictor of exercise: The moderating influence of beliefs and personality variables. Journal of Health Psychology, 4(4), 517-529. https://doi.org/10.1177/135910539900400406

Campo, S., Askelson, N. M., Carter, K. D., \& Losch, M. (2012). Segmenting audiences and tailoring messages: Using the extended parallel process model and cluster analysis to improve health campaigns. Social Marketing Quarterly, 18(2), 98-111. https://doi. org/10.1177/1524500412450490

Cavill, N., \& Bauman, A. (2004). Changing the way people think about health-enhancing physical activity: Do mass media campaigns have a role? Journal of Sports Sciences, 22(8), 771-790. https://doi.org/10.1080/02640410410001712467

Chen, L., Yang, X., Fu, L., Liu, X., \& Yuan, C. (2019). Using the extended parallel process model to examine the nature and impact of breast cancer prevention information on mobile-based social media: Content analysis. JMIR Mhealth and Uhealth, 7(6), article e13987. https://doi. org/10.2196/preprints.13987

Cho, H. (1999). How advertising works on the www: Modified elaboration likelihood model. Journal of Current Issues and Research in Advertising, 21(1), 34-50. https://doi.org/10.1080/106 41734.1999.10505087

Cho, H., \& Salmon, C. T. (2007). Unintended effects of health communication campaigns. Journal of Communication, 57(2), 293-317. https://doi.org/10.1111/j.1460-2466.2007.00344.x

Cialdini, R. B. (2003). Crafting normative messages to protect the environment. Current Directions in Psychological Science, 12(4), 105-109. https://doi.org/10.1111/1467-8721.01242

Compton, J., \& Pfau, M. (2009). Spreading inoculation: Inoculation, resistance to influence, and word-of-mouth communication. Communication Theory, 19(1), 9-28. https://doi.org/10.1111/ j.1468-2885.2008.01330.x

Davenport, T., Guha, A., Grewal, D., \& Bressgott, T. (2020). How artificial intelligence will change the future of marketing. Journal of the Academy of Marketing Science, 48(1), 24-42. https://doi. org/10.1007/s11747-019-00696-0

Dempsey, R. C., McAlaney, J., \& Bewick, B. M. (2018). A critical appraisal of the social norms approach as an interventional strategy for health-related behavior and attitude change. Frontiers in Psychology, 9, 1-16. https://doi.org/10.3389/fpsyg.2018.02180

Dinoff, B., \& Kowalski, R. (1999). Reducing AIDS risk behavior: The combined efficacy of protection motivation theory and the elaboration likelihood model. Journal of Social and Clinical Psychology, 18(2), 223-239. https://doi.org/10.1521/jscp.1999.18.2.223 
Flynn, B. S., Worden, J. K., Bunn, J. Y., Connolly, S. W., \& Dorwaldt, A. L. (2011). Evaluation of smoking prevention television messages based on the elaboration likelihood model. Health Education Research, 26(6), 976-987. https://doi.org/10.1093/her/cyr082

Friedman, A. L., Kachur, R. E., Noar, S. M., \& McFarlane, M. (2016). Health communication and social marketing campaigns for sexually transmitted disease prevention and control: What is the evidence of their effectiveness? Sexually Transmitted Diseases, 43(2S), S83-S101. https:// doi.org/10.1097/OLQ.0000000000000286

Godin, G., Valois, P., Lepage, L., \& Desharnais, R. (1992). Predictors of smoking behaviour: An application of Ajzen's theory of planned behaviour. British Journal of Addiction, 87(9), 1335-1343. https://doi.org/10.1111/j.1360-0443.1992.tb02742.x

Gretz, D., \& Rings, J. (2020). A proposal to evaluate man therapy: A culturally-sensitive intervention to better engage men with psychological services [Graduate presentation, University of Northern Colorado]. Digital UNC. https://digscholarship.unco.edu/cgi/viewcontent. cgi?article $=1002 \&$ context $=$ grad_pres_2020

Hart, P. (2013). Boomerang effects in risk communication. In J. Arvai \& L. Rivers (Eds.), Effective risk communication (pp. 304-318). Routledge.

Henriksen, L., Dauphinee, A. L., Wang, Y., \& Fortmann, S. P. (2006). Industry sponsored anti-smoking ads and adolescent reactance: Test of a boomerang effect. Tobacco Control, 15(1), 13-18. https://doi.org/10.1136/tc.2003.006361

Hickman, A. (2020, May 12). PR pros lambast new government 'stay alert' slogan as 'unclear' and 'unhelpful.' PR week. https://www.prweek.com/article/1682781/pr-pros-lambast-new-government-stay-alert-slogan-unclear-unhelpful

Hornik, R. C., \& Yanovitzky, I. (2003). Using theory to design evaluations of communication campaigns: The case of the national youth anti-drug media campaign. Communication Theory, 13(2), 204-224. https://doi.org/10.1111/j.1468-2885.2003.tb00289.x

Illeditsch, P. K., Ganguli, J. V., \& Condie, S. (2012). Information inertia. Journal of Finance, 76(1), 443-479. http://doi.org/10.2139/ssrn.2084683

Kaplan, A., \& Haenlein, M. (2019). Siri, siri, in my hand: Who's the fairest in the land? On the interpretations, illustrations, and implications of artificial intelligence. Business Horizons, 62(1), 15-25. https://doi.org/10.1016/j.bushor.2018.08.004

Kitchen, P. (2013). The dominant influence of marketing in the 21st century: The marketing leviathan. Palgrave Macmillan.

Kuipers, M.A. G., Beard, E., West, R., \& Brown, J. (2018). Associations between tobacco control mass media campaign expenditure and smoking prevalence and quitting in England: A time series analysis. Tobacco Control, 27(4), 455-462. http://doi.org/10.1136/tobaccocontrol-2017-053662

Loukis, E., Charalabidis, Y., \& Androutsopoulou, A. (2017). Promoting open innovation in the public sector through social media monitoring. Government Information Quarterly, 34(1), 99-109. https://doi.org/10.1016/j.giq.2016.09.004 
Martin, D. (2004). Balancing on the political high wire: The role of humor in the rhetoric of Ann Richards. Southern Communication Journal, 69(4), 273-288. https://doi.org/10.1080/10417940 409373300

McDermott, M. S., Oliver, M., Svenson, A., Simnadis, T., Beck, E. J., Coltman, T., Iverson, D., Caputi, P., \& Sharma, R. (2015). The theory of planned behaviour and discrete food choices: A systematic review and meta-analysis. International Journal of Behavioral Nutrition and Physical Activity, 12(162), 1-11. https://doi.org/10.1186/s12966-015-0324-z

Mocarski, R., \& Butler, S. (2016). A critical, rhetorical analysis of man therapy: The use of humor to frame mental health as masculine. Journal of Communication Inquiry, 40(2), 128-144. https:// doi.org/10.1177/0196859915606974

Morris, J., Woo, C., \& Singh, A. (2005). Elaboration likelihood model: A missing intrinsic emotional implication. Journal of Targeting, Measurement and Analysis for Marketing, 14, 79-98. https:// doi.org/10.1057/palgrave.jt.5740171

Muench, F., \& Baumel, A. (2017). More than a text message: Dismantling digital triggers to curate behavior change in patient-centered health interventions. Journal of Medical Internet Research, 19(5), article e147. https://doi.org/10.2196/jmir.7463

Nielsen, R., Fletcher, R., Newman, N., Brennen, S., \& Howard, P. (2020, April 15). Navigating the 'infodemic': How people in six countries access and rate news and information about coronavirus. Reuters Institute. https://reutersinstitute.politics.ox.ac.uk/infodemic-how-people-six-countries-access-and-rate-news-and-information-about-coronavirus

Orbell, S., \& Sheeran, P. (1998). 'Inclined abstainers': A problem for predicting health-related behaviour. British Journal of Social Psychology, 37(2), 151-165. https://doi. org/10.1111/j.2044-8309.1998.tb01162.x

Pearson, J. C., \& Nelson, P. E. (1999). Introduction to human communication: Understanding and sharing. McGraw-Hill.

Peters, R., Ee, N., Peters, J., Beckett, N., Booth, A., Rockwood, K., \& Anstey, K. J. (2019). Common risk factors for major noncommunicable disease, a systematic overview of reviews and commentary: The implied potential for targeted risk reduction. Therapeutic Advances in Chronic Disease, 10, 1-14. https://doi.org/10.1177/2040622319880392

Petty, R. E., \& Cacioppo, J. T. (1986). The elaboration likelihood model of persuasion. In R. E. Petty \& J. T. Cacioppo (Eds.), Communication and persuasion: Central and peripheral routes to attitude change (pp.1-24). Springer.

Poola, I. (2017) Making artificial intelligence (Al) and disrupted business intelligence (BI) truly conversational with humanity touch, automated descriptions and talking bots. International Journal of Advance Research, Ideas and Innovations in Technology, 3(5), 573-577. https://www. ijariit.com/manuscripts/v3i5/N315-1319.pdf

Prochaska, J. O., \& DiClemente, C. C. (1983). Stages and processes of self-change of smoking: Toward an integrative model of change. Journal of Consulting and Clinical Psychology, 51(3), 390-395. https://doi.org/10.1037/0022-006X.51.3.390 
Rice, R., \& Atkin, C. (2012). Public communication campaigns. Sage Publications.

Rimal, R. N., \& Lapinski, M. (2009). Why health communication is important in public health. Bulletin of the World Health Organization, 87, 247. https://doi.org/10.2471/BLT.08.056713

Rosenstock, I., Strecher, V., \& Becker, M. (1988). Social learning theory and the health belief model. Health Education Quarterly, 15(2), 175-183. https://doi.org/10.1177/109019818801500203

Rowling, J. K. [@jk_rowling]. (2020, May 9). Is Coronavirus sneaking around in a fake moustache and glasses? If we drop our guard, will it slip us a [Image attached] [Tweet]. Twitter. https://twitter. com/jk_rowling/status/1259229863086612480

Rutter, D. (2010). Attendance and reattendance for breast cancer screening: A prospective 3-year test of the theory of planned behaviour. British Journal of Health Psychology, 5(1), 1-13. https://doi.org/10.1348/135910700168720

Schiavo, R. (2007). Health communication: From theory to practice. John Wiley \& Sons.

Sheeran, P., Gollwitzer, P. M., \& Bargh, J. A. (2013). Nonconscious processes and health. Health Psychology, 32(5), 460-473. https://doi.org/10.1037/a0029203

Slater, M. D. (1995). Choosing audience segmentation strategies and methods for health communication. In E. Maibach \& R. Parrott (Eds.), Designing health messages: Approaches from communication theory and public health practice (pp. 186-197). Sage Publications.

Slater, M. D. (1999). Integrating application of media effects, persuasion, and behavior change theories to communication campaigns: A stages-of-change framework. Health Communication, 11(4), 335-354. https://doi.org/10.1207/S15327027HC1104_2

Snyder, L. B. (2007). Health communication campaigns and their impact on behavior. Journal of Nutrition Education and Behavior, 39(2), S32-S40. https://doi.org/10.1016/j.jneb.2006.09.004

Spencer-Thomas, S., Hindman, J., \& Conrad, J. (2012). Man therapy: An innovative approach to suicide prevention for working aged men [White paper]. Man Therapy. https://mantherapy.org/ pdf/ManTherapy.pdf

Spencer-Thomas, S., Hindman, J., \& Conrad, J. (2014). Man therapy: Outreach and impact on men's mental health program 18 months after launch [White paper]. Man Therapy. https://mantherapy. org/pdf/White-Paper-Man-Therapy.pdf

Stead, M., Tagg, S., MacKintosh, A. M., \& Eadie, D. (2005). Development and evaluation of a mass media theory of planned behaviour intervention to reduce speeding. Health Education Research, 20(1), 36-50. https://doi.org/10.1093/her/cyg093

Steindl, C., Jonas, E., Sittenthaler, S., Traut-Mattausch, E., \& Greenberg, J. (2015). Understanding psychological reactance. Zeitschrift Fur Psychologie, 223(4), 205-214. https://doi. org/10.1027/2151-2604/a000222 
Szczepanski, C. M. (2006). General and special interest magazine advertising and the elaboration likelihood model: A comparative content analysis and investigation of the effects of differential route processing execution strategies [Doctoral dissertation, University of New York]. ProQuest. https://www.proquest.com/openview/fbbb27c581c7f4879059702f00621899/1?pq-origsite=g scholar \&cbl=18750\&diss=y

Tench, R., Verčič, D., Zerfass, A., Moreno, A., \& Verhoeven, P. (2017). Communication excellence: How to develop, manage and lead exceptional communications. Palgrave Macmillan.

Wakefield, M. A., Durkin, S., Spittal, M. J., Siahpush, M., Scollo, M., Simpson, J. A., Chapman, S., White, V., \& Hill, D. (2008). Impact of tobacco control policies and mass media campaigns on monthly adult smoking prevalence. American Journal of Public Health, 98(8), 1443-1450. https:// doi.org/10.2105/AJPH.2007.128991

Wakefield, M. A., Loken, B., \& Hornik, R. C. (2010). Use of mass media campaigns to change health behaviour. The Lancet, 376(9748), 1261-1271. https://doi.org/10.1016/S01406736(10)60809-4

Webb, D., \& Byrd-Bredbenner, C. (2015). Overcoming consumer inertia to dietary guidance. Advances in Nutrition, 6(4), 391-396. https://doi.org/10.3945/an.115.008441

Wilson, B. J. (2007). Designing media messages about health and nutrition: What strategies are most effective? Journal of Nutrition Education and Behavior, 39(2), S13-S19. https://doi. org/10.1016/j.jneb.2006.09.001

Witte, K. (1992). Putting the fear back into fear appeals: The extended parallel process model. Communication Monographs, 59(4), 329-349. https://doi.org/10.1080/03637759209376276

Witte, K. (1994). Fear control and danger control: A test of the extended parallel process model (EPPM). Communication Monographs, 61(2), 113-134. https://doi. org/10.1080/03637759409376328

World Health Organization. (n.d.). Infodemic management. https://www.who.int/teams/risk-communication/infodemic-management

Zhao, X. (2020). Health communication campaigns: A brief introduction and call for dialogue. International Journal of Nursing Sciences, 7(1), S11-S15. https://doi.org/10.1016/j. ijnss.2020.04.009 